\title{
PERAHU SAMPAN MENGGUNAKAN DRUM UNTUK MITRA KELOMPOK TANI RUMPUT LAUT DESA LONTAR KECAMATAN TIRTAYASA KABUPATEN SERANG
}

\author{
P. J. Suranto ${ }^{1}$, W. Sulistyawati ${ }^{2}$, Iswadi Nur ${ }^{3}$, dan M Galbi ${ }^{4}$ \\ ${ }^{1}$ Jurusan Teknik Perkapalan, Universitas Pembangunan Nasional Veteran Jakarta \\ Email: purwo.joko@unpnvj.ac.id \\ 2 Jurusan Teknik Perkapalan, Universitas Pembangunan Nasional Veteran Jakarta \\ Email: w12n.sulistyawati.sby@gmail.com \\ ${ }^{3}$ Jurusan Teknik Perkapalan, Universitas Pembangunan Nasional Veteran Jakarta \\ Email: iswadinur62@gmail.com \\ ${ }^{4}$ Jurusan Teknik Mesin, Universitas Pembangunan Nasional Veteran Jakarta \\ Email: galbi_m@yahoo.com
}

\begin{abstract}
The tsunami has occurred on the Banten region coast has damaged many of the boats belonging to seaweed farmers. Many are badly damaged and cannot be repaired, making the income of seaweed farming communities even more difficult. The procurement of a canoe boat requires much money, and the fabrication process is not easy and takes a long time. This community service is carried out to serve in making canoe boats to seaweed farmers by utilizing used drums. This activity was carried out in a seaweed farmers group in Lontar village, Serang district, Banten province. Lontar Village is located on the beach in an area of 556.5 hectares. The number of families about 1,837 and the poor amounted to 1,534 of families or around $84 \%$ of the total population. This community service begins with a location survey, providing counselling and assistance in making canoe boats using used drums. The process of this activity involves the partners of the seaweed farmer groups which the Partners and residents hope to complement each other and independently build canoe boats. Making a canoe boat with used drums takes a moderately short time and is cheap and has a reasonably good safety factor. The sampan boat is made of long 3,325 m, wide $1 \mathrm{~m}$, high $0.6 \mathrm{~m}$, draft $0.35 \mathrm{~m}, 723 \mathrm{~kg}$ displacement and with a speed of 3 knots. This manufacturing process has functioned through a design calculation process that meets the right criteria so that the canoe boat is safe to use.
\end{abstract}

Keywords: Lontar village, canoes, used drums, cheap and safety.

\begin{abstract}
ABSTRAK
Tsunami Pernah terjadi di pesisir pantai wilayah Banten, perahu-perahu sampan milik petani rumput laut banyak yang rusak dan tidak bisa digunakan lagi sehingga sampai sekarang pendapatan masyarakat petani rumput laut masih rendah. Dalam mengelola rumput laut yang terletak agak ke tengah laut dibutuhkan perahu sampan untuk mencapainya. Pengadaan perahu sampan membutuhkan biaya yang besar dan proses pembuatannya tidak mudah. Pengabdian masyarakat dilakukan untuk memberikan pendampingan dalam pembuatan perahu sampan kepada petani rumput laut dengan memanfaatkan drum-drum bekas.. Kegiatan ini dilakukan di kelompok petani rumput laut di desa Lontar kabupaten Serang provinsi Banten. Wilayah desa Lontar terletak di pinggir pantai dengan luas wilayah 556.5 Ha. Sedangkan jumlah kepala keluarga 1.837 dengan jumlah masyarakat miskin 1.534 kepala keluarga atau sekitar $84 \%$. Pengabdian masyarakat ini diawali dengan survey lokasi dan kemudian melakukan penyuluhan serta pembuatan perahu sampan dengan menggunakan drum. Dalam proses kegiatan ini melibatkan Mitra kelompok petani rumput laut, sehingga diharapkan mereka nantinya bisa membuat perahu sampan. Pembuatan perahu sampan dengan drum ini memakan waktu yang cukup singkat dan murah serta mempunyai faktor keamanan yang baik. Perahu sampan yang terbuat dari drum di desain dan dibuat dengan ukuran pokoknya sebagai berikut: panjang 3.325 meter, lebar 1 meter, tinggi 0.65 meter, sarat air 0.35 dengan kecepatan 3 knot dan displasemen $723 \mathrm{~kg}$. Sebelum proses pembuatan tentunya perahu sampan ini sudah melalui proses perhitungan desain yang memenuhi kriteria baik sehingga perahu sampan yang terbuat dari drum ini aman untuk digunakan.
\end{abstract}

Kata kunci: Desa Lontar, sampan, drum bekas, murah dan aman.

\section{PENDAHULUAN}

Tsunami Pernah terjadi di pesisir pantai wilayah Banten, perahu-perahu termasuk perahu sampan milik petani rumput laut banyak yang rusak dan tidak bisa digunakan lagi sehingga sampai sekarang pendapatan masyarakat petani rumput laut di pesisir pantai wilayah Banten pada umumnya masih rendah. Disebabkan masih perahu-perahu sampan banyak yang rusak dan tidak 
bisa digunakan lagi, sehingga sulit bagi mereka untuk melaut dalam rangka mencari nafkah guna menafkahi keluarga mereka.

Dalam rangka mempercepat pemulihan perekonomian petani rumput laut di wilayah pesisir pantai Banten terutama desa Lontar kecamatan Tirtayasa kabupaten Serang. Sangat dibutuhkan perahuperahu sampan yang cukup banyak untuk menunjang kegiatan mereka dalam menanam dan mengelola rumput laut. Maka solusinya adalah dicari alternatif pembuatan perahu sampan yang mudah dan cepat pembuatannya, murah harganya, serta baik dan aman digunakan, ini sesuai dengan Program Peningkatan Kehidupan Nelayan (PKN) yang sebelumnya telah ditetapkan dan Kepres Nomor 10 tahun 2011 [2].

Lahan-lahan mereka berada di tengah laut sehingga untuk menanam serta mengelola rumput laut tersebut dibutuhkan perahu-perahu sampan.

\section{METODE PELAKSANAAN PKM}

Metode Pelaksanaan dari Pengabdian Masyarakat ini dapat dilihat pada diagram alir sebagaimana ditampilkan pada Gambar 1.

\section{Gambar 1}

\section{Skema Metode Pelaksanaan Pengabdian Kepada Masyarakat}

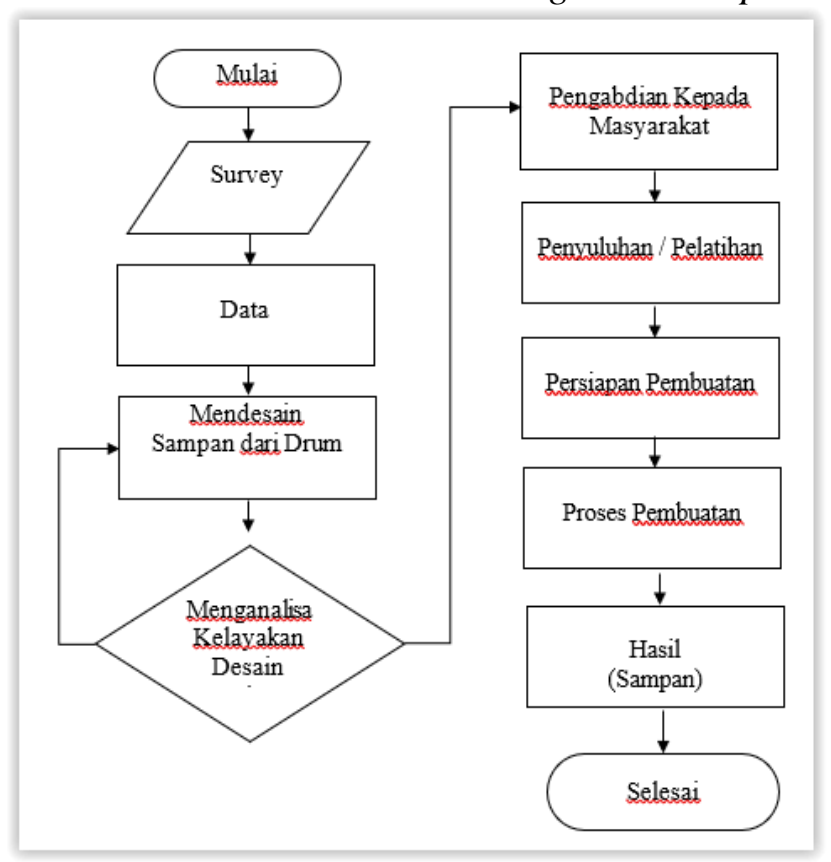

\section{Survey Lokasi}

Dilakukan untuk memetakan apakah pelaksanaan Pengabdian kepada Masyarakat tepat sasaran. Survey lokasi dilaksanakan di desa Lontar kecamatan Tirtayasa, Kabupaten Serang, Provinsi Banten.

Menurut Sumber dari Desa Lontar didapatkan Profil masyarakat Desa Lontar, Kecamatan Tirtayasa, Kabupaten Serang, Provinsi Banten dan diperoleh data sebagai berikut: Wilayah desa Lontar terletak di pinggir pantai dengan luas wilayah desa Lontar adalah 556,5 Ha. Sedangkan jumlah kepala keluarga ada 1.837 kepala keluarga dengan jumlah masyarakat miskin 1.534 kepala keluarga atau 84\% masyarakatnya adalah tergolong masyarakat miskin. Data mata pencaharian atau jenis pekerjaan masyarakat desa Lontar dapat dilihat pada Tabel 1. 


\section{Tabel 1}

Mata Pencaharian atau Jenis Pekerjaan Masyarakat Desa Lontar

\begin{tabular}{ll}
\hline JENIS PEKERJAAN & JUMLAH (Orang) \\
\hline Nelayan & 1.327 \\
Buruh Nelayan & 852 \\
Petani Rumput Laut & 1.021 \\
Karyawan & 50 \\
Wiraswasta/pedagang & 80 \\
TNI / Polri & 7 \\
Buruh Migran & 1.029 \\
Tani & - \\
Buruh Tani & 20 \\
Pertukangan & 25 \\
Pensiunan & 9 \\
Pemulung & 4 \\
Tk.Ojek & 54 \\
Guru Swasta & 26 \\
Guru Ngaji & 38 \\
Bidan & 1 \\
Jasa & 14 \\
Pelajar / Mahasiswa & 2.201 \\
Tidak Bekerja & 234 \\
\hline
\end{tabular}

Proses Desain Perahu Sampan untuk petani rumput laut di desa Lontar sebagai berikut :

1) Menentukan Ukuran Utama Perahu Sampan untuk digunakan oleh petani rumput laut.

2) Menghitung Muatan perahu sampan.

3) Menghitung Kekuatan perahu sampan.

4) Menghitung Stabilitas Perahu sampan

5) Menganalisa kelayakan perahu sampan

Adapun Proses Pembuatan perahu sampan untuk masyarakat desa Lontar, Kecamatan Tirtayasa, Provinsi Banten sebagai nerikut :

1) Penyuluhan mengenai pembuatan perahu sampan.

2) Persiapan Peralatan dan bahan yang dibutuhkan untuk pembuatan perahu sampan.

3) Pengerjaan pembuatan perahu sampan Bersama masyarakat desa Lontar.

4) Hasil berupa perahu sampan untuk petani rumput laut di desa Lontar, kecamatan Tirtayasa, Kabupaten Serang, Provinsi Banten.

\section{Gambar 2}

\section{Pemodelan Perahu Sampan}

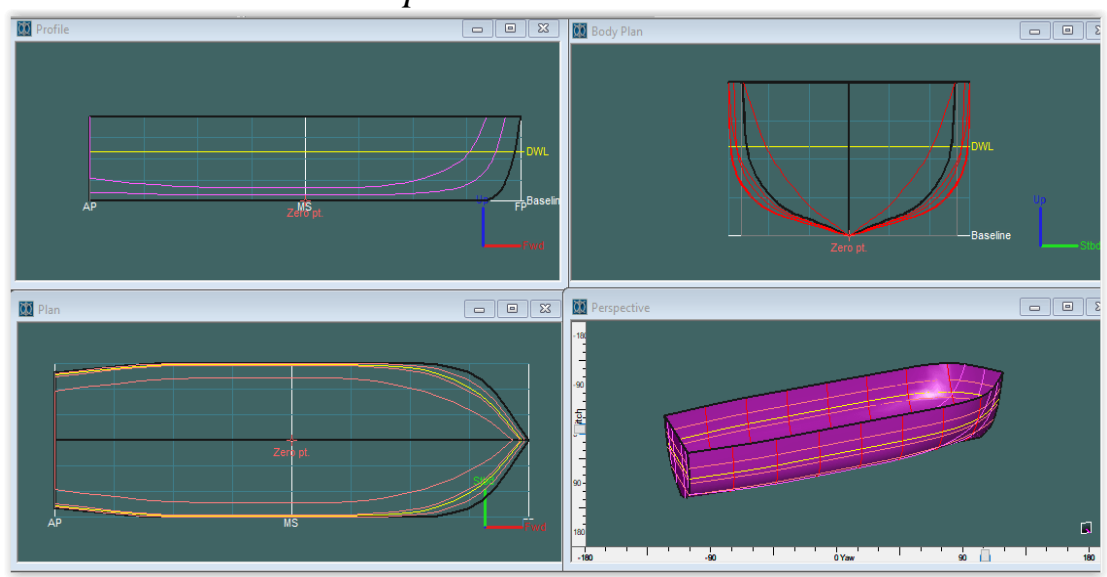




\section{HASIL DAN PEMBAHASAN}

\section{Proses Desain Perahu}

Desain perahu sampan dimodelkan menggunakan software dibidang perkapalan yaitu software Maxsurf sebagaimana diperlihatkan pada Gambar 2.

\section{Tabel 2}

Hasil Analisa Lambung Menggunakan Software

\begin{tabular}{ll}
\hline Displacement & $0.723 \mathrm{t}$ \\
\hline Volume (displaced) & $0.705 \mathrm{~m} 3$ \\
\hline Draft Amidships & $0.350 \mathrm{~m}$ \\
\hline Tinggi Perahu & $0,603 \mathrm{~m}$ \\
\hline WL Length & $3.187 \mathrm{~m}$ \\
\hline Beam max extents on WL & $0.981 \mathrm{~m}$ \\
\hline Wetted Area & $3.891 \mathrm{~m} 2$ \\
\hline Prismatic coeff. (Cp) & 0.853 \\
\hline Block coeff. (Cb) & 0.644 \\
\hline Max Sect. area coeff. (Cm) & 0.756 \\
\hline Waterpl. area coeff. (Cwp) & 0.896 \\
\hline Kecepatan & 3 Knot \\
\hline
\end{tabular}

\section{Perhitungan Hambatan dan Power Perahu}

Perahu yang sudah dimodelkan di Maxsurf Modeler tersebut kemudian dianalisis menggunakan Maxsurf Resistance, dari hasil Analisa didapatkan sebagaimana terlihat pada Gambar 3.

Gambar 3

\section{(a) Grafik Hambatan dan Kecepatan (b) Grafik Tenaga dan Kecepatan Perahu Sampan}

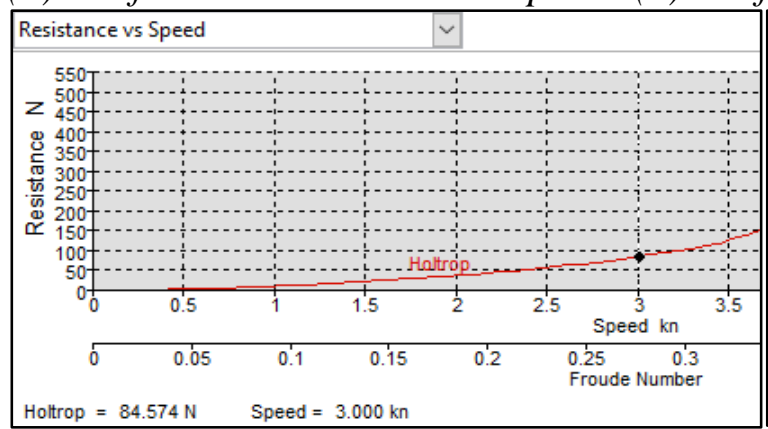

(a)

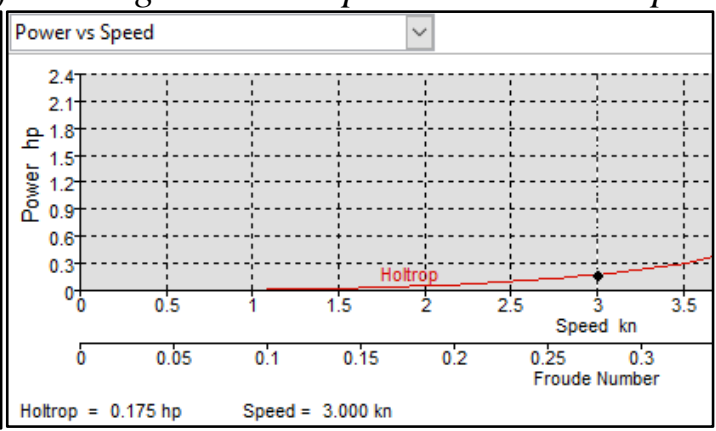

(b)

Berdasarkan Gambar 3(a) menunjukan bahwa besarnya Hambatan Perahu pada kecepatan 3 Knot adalah 84,574 Newton (N) sedangkan Efektif Horse Power sesuai Gambar 3(b) (EHP) perahu sampan tersebut 0,175 Horse Power (HP). Delivery Horse Power (DHP) adalah daya yang di serap oleh baling-baling perahu guna menghasilkan Daya Dorong, dihitung dari perbandingan antara Daya Efektif atau EHP dengan Koefisien Propulsif atau PC sekitar 0,615, jadi:

$$
\begin{aligned}
\mathrm{DHP} & =\mathrm{EHP} / \mathrm{PC} \\
& =0,175 \mathrm{HP} / 0.615 \\
\mathrm{DHP} & =0,285 \mathrm{HP}
\end{aligned}
$$

Shaft Horse Power (SHP) adalah daya yang terukur pada poros dan ini akan kehilangan daya sekitar 2\% sampai 3\%, perahu menggunakan mesin outboard atau mesin tempel sehingga kehilangan daya pada poros kecil maka diambil $2 \%$. Sehingga harga efisiensi pada poros atau $\eta$ sүb adalah 0,98 maka: 


$$
\begin{aligned}
\mathrm{SHP} & =\mathrm{DHP} / \eta \mathrm{s} \eta \mathrm{b} \\
& =0,285 \mathrm{HP} / 0,98 \\
\mathrm{SHP} & =1,019 \mathrm{HP}
\end{aligned}
$$

Brake Horse Power (BHP) adalah daya rem (Brake Power). Sistem roda gigi pada mesin tempel atau outboard menggunakan gigi reduksi tunggal atau Single Reduction Gear dengan loss $2 \%$ atau bisa disebut juga efisiensi gear (ng) adalah 98\%. BHPscr adalah daya output dari motor penggereak pada kondisi Continues Servis Rating, maka:

$$
\begin{aligned}
\text { BHPscr } & =\mathrm{SHP} / \eta \mathrm{g} \\
& =1,019 \mathrm{HP} / 0.98 \\
& =1,04 \mathrm{HP}
\end{aligned}
$$

Besarnya daya motor penggerak utama atau motor induk ini adalah daya keluaran pada pelayaran normal atau SCR, dimana besarnya adalah $80 \%$ - 85\% dari daya keluaran pada kondisi maksimum atau MCR jadi daya keluaran pada kondisi BHPmcr adalah:

$$
\begin{aligned}
\text { BHPmcr } & =\text { BHPscr } / 0.85 \\
& =1,04 \mathrm{HP} / 0.85 \\
& =1,224 \mathrm{HP} \text { dibulatkan menjadi } 1,5 \mathrm{HP}
\end{aligned}
$$

Digunakan Mesin yang ada dipasaran adalah 1,5 HP dengan spesifikasi seperti pada Tabel 3.

\section{Tabel 3}

Spesifikasi Mesin Penggerak

\begin{tabular}{ll}
\hline Tenaga $2 \mathrm{hp} / \mathrm{pk}$ & Gear RatEstimated Speed 5 10 mph or knot \\
\hline Max Prop Shaft Output 1.5 kw @ 4500 r/m & Propeller Pitch Size 5" \\
\hline Engine Type 1 Cylinder - 2 Tak / Stroke (outboard) & Compression Ratio 8.3 \\
\hline Fuel Tank Built in Fuel Tank - 1.4L & Displacement 50 cc \\
\hline Jenis Bahan Bakar Bensin / Gasoline & Shaft Length Short - 15" \\
\hline Fuel Consumption 1.3 litres per hour & Dry Weight 9.8 kg \\
\hline Gear Shift Forward - Netral - Reverse & \\
\hline
\end{tabular}

\section{Gambar 4}

Mesin Outboard yang Digunakan

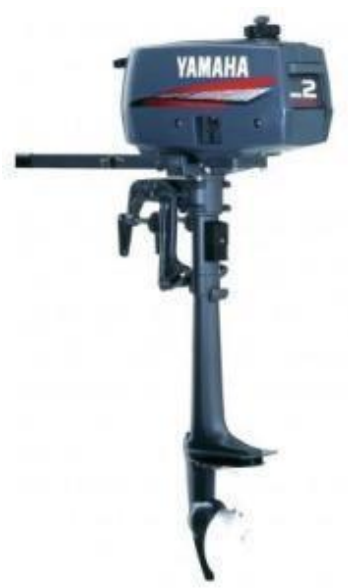

Sumber: yamaha.com, 2020 


\section{Perhitungan Berat LWT Perahu}

Adapun Berat LWT (Light Weight Tonnage) Perahu bisa dihitung sebagai berikut:

- Berat Drum

1 Jerigen 7,5 kg. Dibutuhkan 4 drum jadi berat jerigen total $=7,5 \mathrm{~kg}$ x $4=30 \mathrm{~kg}$.

- Berat Kayu

Kayu yang digunakan kamfer, kayu ini mempunyai berat jenis $0,7-0,9 \mathrm{gr} / \mathrm{cm}^{3}$

Diambil $0,8 \mathrm{gr} / \mathrm{cm} 3$

Berat Lunas $=(320 \mathrm{~cm} \times 6 \mathrm{~cm} \times 4 \mathrm{~cm}) \times 0,8 \mathrm{gr} / \mathrm{cm}^{3}=6144 \mathrm{gr}=6,15 \mathrm{~kg}$

Berat Frame $=(60,3 \mathrm{~cm} \times 98,1 \mathrm{~cm} \times 3 \mathrm{~cm} \mathrm{x} 4) \times 0,8 \mathrm{gr} / \mathrm{cm}^{3}=56788 \mathrm{gr}=56,8 \mathrm{~kg}$

Jadi berat kayu total $=6,15 \mathrm{~kg}+56,8 \mathrm{~kg}=64,95 \mathrm{~kg}$. dibulatkan $65 \mathrm{~kg}$

- Berat Mesin

Sesuai dengan perhitungan Hambatan badan kapal, maka digunakan mesin outboard yang powernya 2 HP sebagaimana Gambar 4. serta dilihat dari spesifikasinya maka berat mesin yang digunakan adalah $9,8 \mathrm{~kg}$.

Maka berat LWT perahu $=30 \mathrm{~kg}+65 \mathrm{~kg}+9,8 \mathrm{~kg}=104,8 \mathrm{~kg}$.

\section{Perhitungan Berat Dead Weight Tonnage (DWT)}

Adapun Berat DWT (Dead Weight Tonnage) Perahu bisa dihitung sebagai berikut:

- Berat Orang

Perahu ini direncanakan mengangkut 2 orang nelayan.

Berat 1 org diambil yang terberat $150 \mathrm{~kg}$

Berat orang $=2$ org $\times 150 \mathrm{~kg}=300 \mathrm{~kg}$

- Berat Bahan Bakar Mesin

Berat Bahan Bakar (BBM) sesuai Consumable dari mesin yang digunakan yaitu 1,3 liter/jam dan perahu ini harus mampu beroperasi 7 jam maka didapat:

Jumlah BBM = 1,3 liter/jam x 7 jam = 11,17 liter

Cadangan BBM 10\% = 11,17 x 10/100 = 1,117 liter

Total $\mathrm{BBM}=11,17+1,117=12,287$ liter dibulatkan 13 liter

Berat Jenis BBM Bensin Premium adalah 0,75-0,76 kg/liter

Maka Berat BBM 0,75 kg/liter x $13 \mathrm{~kg}=9,75 \mathrm{~kg}$ dibulatkan $10 \mathrm{~kg}$.

- Berat Air Tawar + Makanan

Air Tawar untuk kosumsi diperkirakan 1 org 5 liter, jadi untuk 2 orang $=10$ liter

Bahan Makanan diperkirakan $5 \mathrm{~kg}$ untuk 2 orang.

Maka Berat air tawar + makanan $=15 \mathrm{~kg}$.

Maka berat DWT perahu sampan $=300 \mathrm{~kg}+10 \mathrm{~kg}+15 \mathrm{~kg}=325 \mathrm{~kg}$.

Berat Kapal keseluruhan $=114,3+325=439,3 \mathrm{~kg}$

Sedangkan displasemen kapal sesuai Analisa dengan maxsurf adalah $723 \mathrm{~kg}$ (Tabel 2). Maka perahu masih bisa dimuati dengan muatan sebesar $=723 \mathrm{~kg}-439,3=283,7 \mathrm{~kg}$ muatan cadangan. Berat muatan cadangan ini dimaksudkan apabila ada penambahan muatan misalkan penambahan orang atau barang dan lain sebagainya. Berat cadangan adalah minimal 30\% dari berat muatan [3]. Jadi $30 \%$ dari $300 \mathrm{~kg}$ adalah ton sama dengan $90 \mathrm{~kg}$. sedangkan perahu masih bisa dimuati 283,7 $\mathrm{kg}$, sehingga dalam hal ini sangat aman jika hanya dimuati $90 \mathrm{~kg}$.

\section{Perhitungan Karakteristik Perahu}

Perahu yang sudah dimodelkan di Maxsurf Modeler tersebut kemudian dianalisa menggunakan Maxsurf Stability, dari hasil Analisa didapatkan diagram atau kurva Karakteristik kapal atau sering disebut kurva Hidrostatik, sebagaimana ditampilkan pada Gambar 5(a). 


\section{Gambar 5}

\section{(a) Kurva Hidrostatik Perahu Sampan (b) Kurva Stabilitas Perahu Sampan}

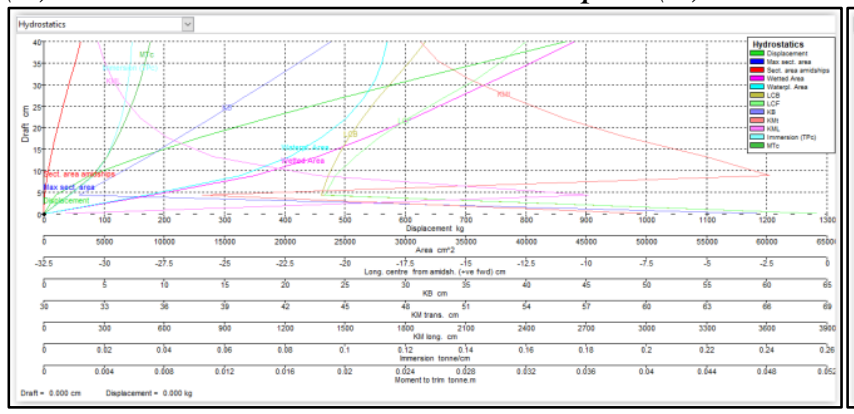

(a)

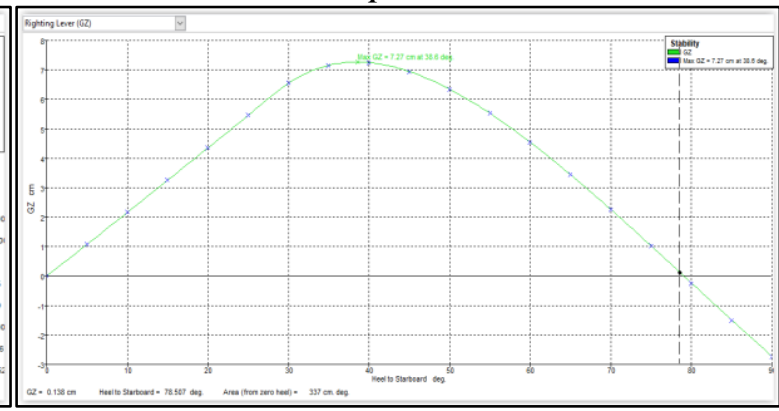

(b)

Dengan Kurva Hidrostatik tersebut maka kita bisa membaca berbagai macam karakteristik perahu sampan yang kita buat misalnya kita dapat mengetahui berat perahu, titik berat perahu maupun titik berat volume badan kapalyang tercelup air, momen perahu dan lain sebagainya.

\section{Perhitungan Stabilitas Perahu}

Perahu yang sudah dimodelkan di Maxsurf Modeler tersebut kemudian dianalisa menggunakan Maxsurf Stability, dari hasil Analisa didapatkan sebagaimana Gambar 5(b). Dengan Kurva stabilitas perahu sampan tersebut maka kita bisa mengetahui sampai kemiringan berapa derajat kapal tersebut sudah tidak stabil artinya batas derajat kemiringan pada gambar 7 dapat dilihat bahwa batas stabilitas kemiringan perahu sampan yang dibuat adalah 78 derajat artinya apabila perahu tersebut miring diatas 78 derajat maka perahu tersebut akan tenggelam, jadi batas maximum kapal tersebut miring adalah 78 derajat sehingga stabilitas perahu tersebut dapat dikatakan sangat baik.

\section{Proses Pembuatan Perahu Sampan}

Pembuatan Perahu sampan ini dilaksanakan di desa Lontar kecamatan Tirtayasa, Kabupaten Serang, Provinsi Banten dengan melibatkan masyarakat desa tersebut, dengan proses pembuatannya sebagai berikut:

1) Penyuluhan

Penyuluhan dimaksudkan agar masyarakat di daerah tersebut memahami langkah-langkah pembuatan perahu sampan. Kegiatan penyuluhan dapat dilihat pada Gambar 6.

2) Pelatihan Pembuatan

Pelatihan pembuatan sampan dari drum dilakukan pada hari berikutnya. Langkah-langkah:

i. Pembuatan Mal Penggaris dari kayu yang berbentuk T dan diberi paku untuk menggores permukaan drum.

ii. Pembuatan garis pada permukaan drum yang nantinya akan dipotong, pembuatan garis tersebut dengan menggunakan Mal yg telah dibuat sebelumnya.

iii. Drum yang sudah digaris sebelumnya kemudian dipotong pada bagian atas dan bagian bawah drum dengan menggunakan gergaji mesin sehingga dihasilkan drum yang sudah terpotong.

iv. Bagian pinggiran drum yang telah dipotong dihaluskan dengan mesin serut.

v. Drum dipotong memanjang dengan mesin gergaji.

vi. Pembuatan garis untuk penempatan lunas, dan garis tersebut harus dipertebal agar drum mudah untuk ditekuk.

vii. Pembuatan lunas yang terbuat dari kayu dan drum yg sudah diberi garis tekukan diletakkan dan dipasang di lunas yang terbuat dari kayu tersebut yang sudah dipasangi karet ban dalam. 
viii. Drum dipaku di bagian yang terdapat karet ban dalam dan kemudian dilanjutkan dengan dipaku di lunas sehingga drum menempel pada lunas.

ix. Drum pada bagian lunas di tekuk dengan terlebih dahulu di garis dengan mesin gerinda yang bertujuan drum mudah ditekuk pada bagian bentuk lunas.

x. Proses pembuatan gading-gading yang dibuat menggunakan kayu dan akan dipasang di atas lunas. Gading yang menempel dengan lunas dibuat coakan agar bisa dipasang di lunas dengan baik.

xi. Gading dipasang ke lunas menggunakan paku kemudian pada pertemuan gading dan drum diberi karet ban terus dipaku agar drum menempel pada gading (frame).

xii. Pasang drum berikutnya kemudian pasang gading berikutnya lagi, terus berulangulang sampai ke depan atau haluan perahu, setiap sambungan diberi damar agar tidak bocor.

Dokumentasi langkah-langkah pembuatan perahu sampan dapat dilihat pada Gambar 7 hingga Gambar 10. Hasil akhir perahu sampan dapat dilihat pada Gambar 11.

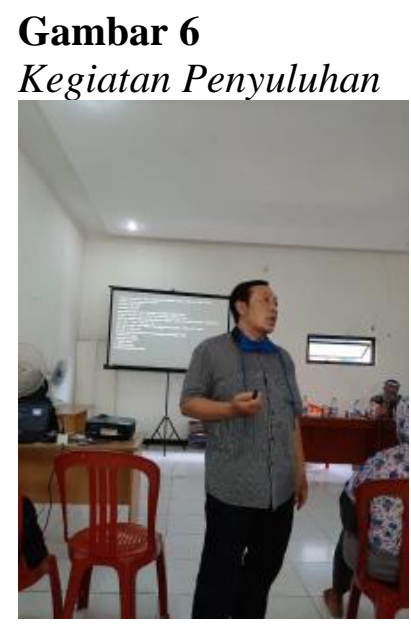

\section{Gambar 7}

(a) Langkah i (b) Langkah ii (c) Langkah iii

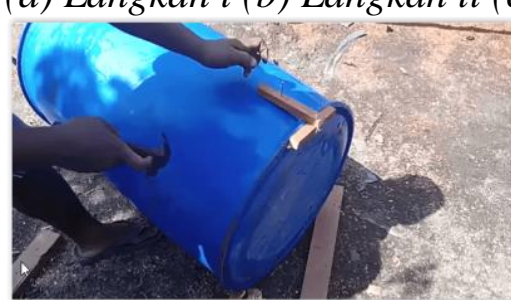

(a)

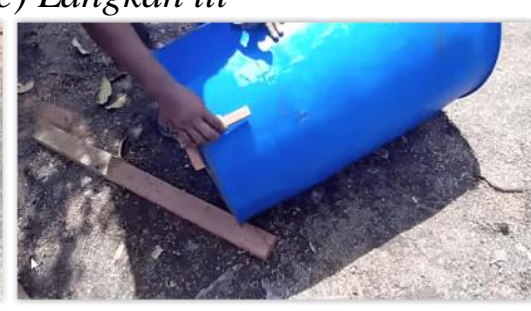

(b)

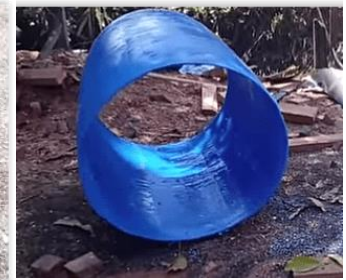

(c)

\section{Gambar 8}

(a) Langkah iv (b) Langkah v (c) Langkah vi

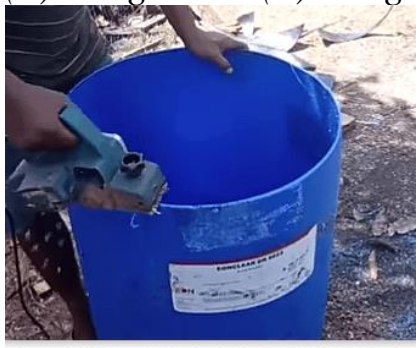

(a)

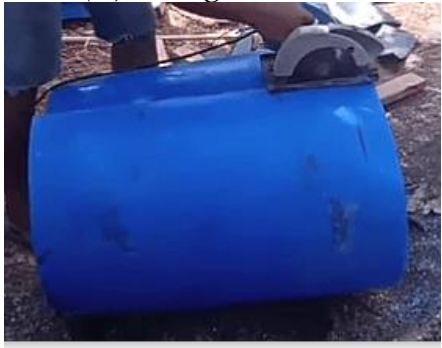

(b)

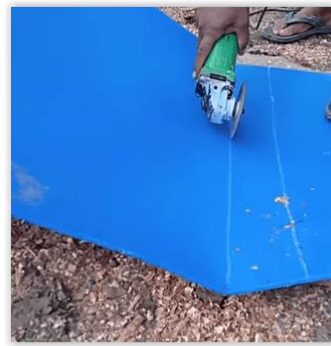

(c) 


\section{Gambar 9}

(a) Langkah vii (b) Langkah viii (c) Langkah ix

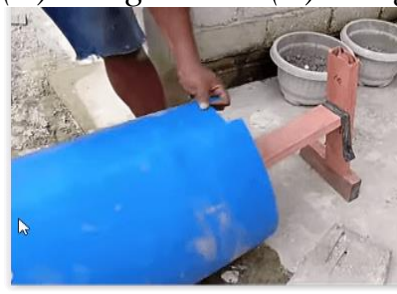

(a)

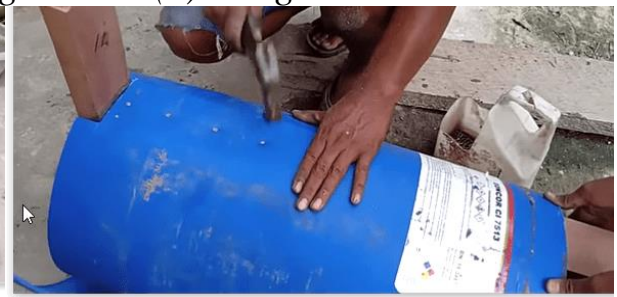

(b)

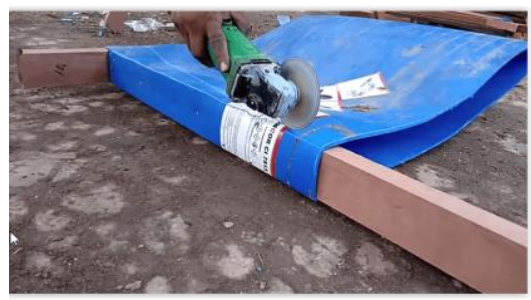

(c)

\section{Gambar 10}

\section{(a) Langkah $x$ (b) Langkah xi (c) Langkah xii}

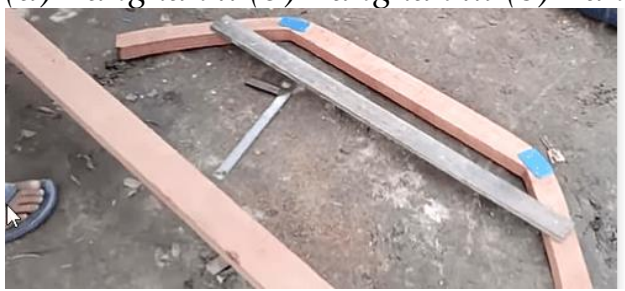

(a)

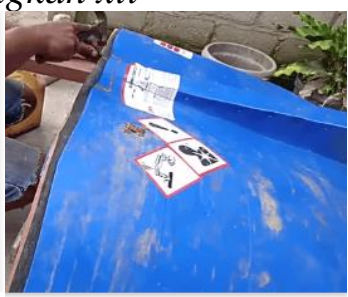

(b)

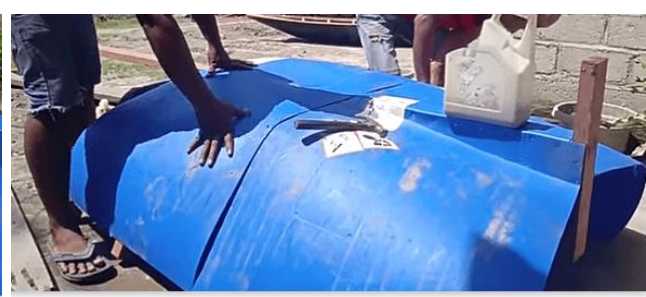

(c)

\section{Gambar 11}

\section{Hasil Akhir Perahu Sampan}

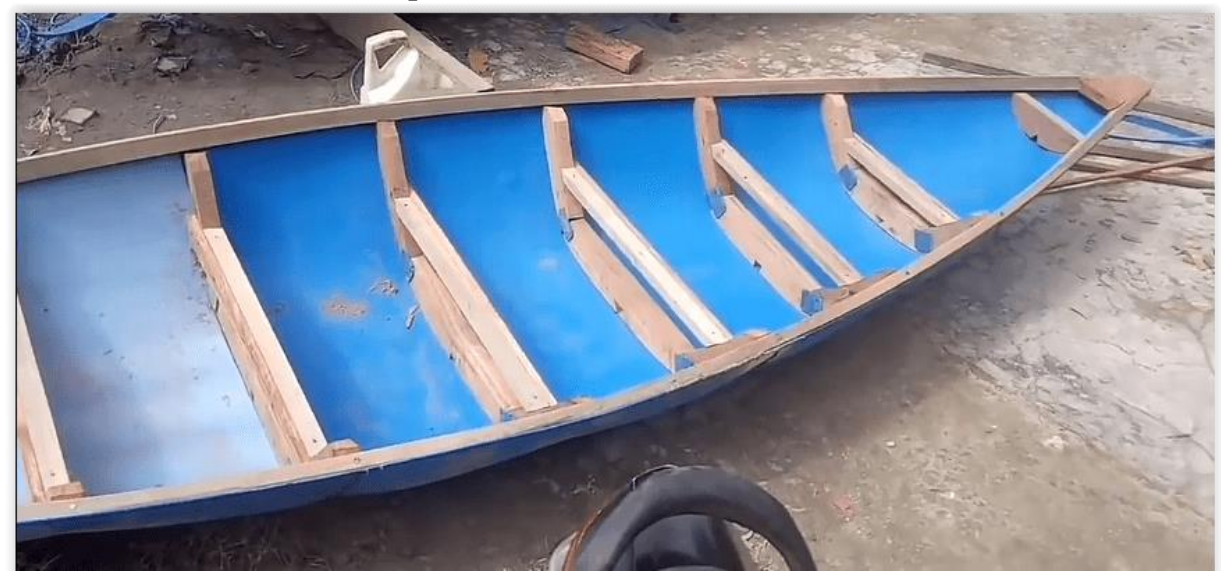

\section{KESIMPULAN DAN SARAN}

\section{Kesimpulan}

Pembuatan perahu sampan ini membutuhkan drum sebanyak 4 drum serta kayu dan sdikit serat fiber. Peruahu dimodelkan menggunakan software maxsurf dengan ukuran pokok $\mathrm{L}=.3,2 \mathrm{~m}$; $\mathrm{B}=0,981 \mathrm{~m} ; \mathrm{H}=0,603 \mathrm{~m} ; \mathrm{T}=0,35 \mathrm{~m} ; \mathrm{Cb}=0,644$; Displacement $=0,723$ ton. Serta mampu mengangkut 2 orang. Mempunyai stabilitas serta kekuatan yang baik sehingga aman untuk digunakan oleh petani rumput laut desa Lontar kecamatan Tirtayasa, kabupaten Serang, provinsi Banten.

Pembuatan perahu sampan dilaksanakan di desa Lontar Kecamatan Tirtayasa, kabupaten Serang, Provinsi Banten. Adapun proses pembuatan perahu sampan tersebut adalah sebagai berikut: 1 . melakukan penyuluhan kepada masyarakat, 2. Melakukan pelatihan dengan melibatkan masyarakat desa tersebut. Hasil pembuatan perahu sampan tersebut mempunyai karakteristik yang baik sehingga aman digunakan oleh petani rumput laut. 


\section{Saran}

Minimnya dana yang diterima untuk melakukan pengmas ini sehingga tidak maksimal dalam pelaksanaan dan hasil dari pengmas ini, sehingga kedepannya perlu ditinjau kembali dana yang diberikan agar hasilnya bisa maksimal sesuai harapan kita semua, bagaimanapun juga pengmas ini sangat bermanfaat bagi desa-desa di mana kita melakukan pengmas dan semoga berlanjut kedepannya bisa lebih baik lagi.

\section{Ucapan Terima Kasih (Acknowledgement)}

Terimakasih kepada semua pihak yang telah ikut membantu terlaksananya kegiatan Pengabdian Kepada Masyarakat ini, terutama kepada Lembaga Penelitian dan Pengabdian (LP2M) Universitas Pembangunan Nasional Veteran Jakarta yang telah mendanai pengmas ini, juga kepada Kepala Desa Lontar serta Ketua koperasi Desa Lontar yang telah mengijinkan pengabdian masyarakat ini dilaksanakan di desa Lontar.

\section{REFERENSI}

Derrett, D. R., \& Barras, C. B. (2006). Ship stability for masters and mates. Elsevier Butterworth. Suranto, P.J., \& Sudjasta, B. (2018). Perahu nelayan menggunakan jerigen bekas untuk meningkatkan kesejahteraan nelayan. Bina Teknika, 14(2), 193-198.

Nur, I., Suranto, P. J., \& Marasabessy, A. (2019). Rancangan konstruksi kapal penangkap ikan 60 GT untuk nelayan pelabuhan perikanan nusantara karangantu kota Serang. Jurnal Ilmiah Giga, 22(2), 85-92. http://dx.doi.org/10.47313/jig.v22i2.771.

Suranto, P. J., \& Nur, I. (2017). Perancangan perahu berbahan fiberglass berlapis karet untuk evakuasi bencana banjir. Bina Teknika, 13(1), 95-99.

Nur, I. and Sunarto, P.J. (2018). Design of fishing boat for Pelabuhanratu Fishermen as one of effort to increase production of capture fisheries. Journal of Physics: Conference Series, 962(2018), 1-8.

Holtrop, J., \& Mennen, G. G. J. (1982). An approximate power prediction method, International Shipbuilding Progress, 29(335), 166-170. 